\title{
CATALYSIS AND CAPACITANCE OF NANOSTRUCTURED GOLD SPONGES
}

\author{
M.B. CORTIE \\ Institute for Nanoscale Technology, UTS, PO Box 123, Broadway NSW 2007, Australia \\ E. VAN DER LINGEN AND G. PATTRICK \\ Physical Metallurgy Division, Mintek, Private Bag X3015, Randburg 2125, South Africa
}

\begin{abstract}
In the present paper we describe the catalytic properties and electrolytic double-layer capacitance of nano-structured, mesoporous gold sponges. These materials are effective catalysts for $\mathrm{CO}$ oxidation, and for the selective catalytic conversion of NOx. The possible application of mesoporous gold in electric double layer capacitors is premised on its high surface area, corrosion resistance and excellent electrical conductivity. The niche, if any exists, would be in high-efficiency, and high-power density ultra-capacitors for top-end consumer appliances.
\end{abstract}

\section{Introduction}

The properties of metals in nano-particulate form are currently receiving much attention. However, the inverse situation, that of a mesoporous metal skeleton containing nano-scale cavities, has scarcely been investigated. Nevertheless, such mesoporous materials have been known since at least 1927, when Raney patented his famous nickel hydrogenation catalyst produced by de-alloying $\mathrm{Ni}_{\mathrm{x}} \mathrm{Al}_{\mathrm{y}}$ with $\mathrm{NaOH}^{1}$. 'Raney copper' and 'Raney platinum' may be produced by an analogous process ${ }^{2}$. Generally the resulting nanoscale sponge is pyrophoric and must be handled with care. However, mesoporous gold is a rare exception to this rule, and it has recently been shown that non-combustible, mesoporous sponges may be produced by de-alloying an $\mathrm{AuAl}_{2}$ intermetallic precursor ${ }^{3,4}$. The result is a skeletal gold network, characterized by a continuous network of channels of nanoscale dimensions. In this paper we will describe the properties and possible uses of this mesoporous gold sponge.

\section{Anomalous properties of mesoporous gold}

Bulk gold is yellow and melts at $1064^{\circ} \mathrm{C}$. However, these 'facts' do not apply to the sponge. For example, the melting point of nano-structured gold protrusions or particles of $5 \mathrm{~nm}$ radius is reduced by up to $400^{\circ} \mathrm{C}^{5}$. In combination with the well-known high mobility of Au surface atoms (due to their reluctance to bond with atmospheric gases), the net effect is that mesoporous gold sponges are relatively unstable with regard to sintering. When freshly prepared mesoporous gold is black, and in this state is one of the best absorbers known of infra red 
radiation $^{6}$. However, unless the mesoporous state is stabilized by some coating substance, such as sodium citrate, aluminum oxide or copper oxide, the black gold has a tendency to sinter to the denser yellow form.

The size distribution of the channels in a sample with a BET surface area of $20 \mathrm{~m}^{2} / \mathrm{g}$ is shown in Figure 1. It is evident that this material consists of a large number of nominally $13 \mathrm{~nm}$ diameter cavities embedded in a matrix of gold.

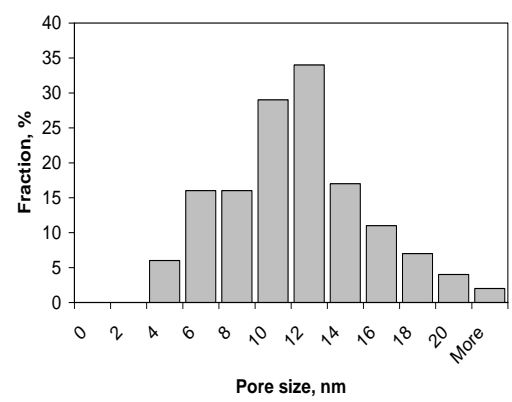

FIGURE 1. Channel sizes in meso-porous gold surface prepared by de-alloying of $\mathrm{AuAl}_{2}$ in $1 \mathrm{M} \mathrm{NaOH}$. Sample has been dried out for SEM examination but has been ostensibly stabilized by about $5 \mathrm{wt} \% \mathrm{Al}_{2} \mathrm{O}_{3}$.

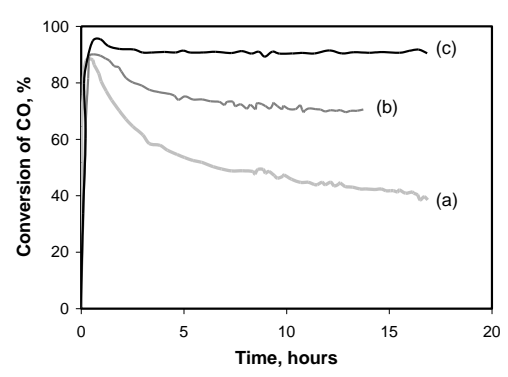

Figure 2. Oxidation of $1 \%$ carbon monoxide in air at $60^{\circ} \mathrm{C}$. The space velocity is $91 . \mathrm{g}^{-1} \cdot \mathrm{h}^{-1}$;

(a) commercial hopcalite, (b) hopcalite on which gold nanoparticles have been deposited, (c) mechanically alloyed composite of hopcalite and mesoporous gold

\section{Catalysis}

It was only discovered in the 1980s that gold nano-particles can be active heterogeneous catalysts ${ }^{7,8}$. On the face of it, the nobility of metallic gold makes it an unlikely candidate for heterogeneous catalysis. However, gold particles of less than $10 \mathrm{~nm}$ diameter have now been shown to be active catalysts for diverse chemical reactions ${ }^{9}$, of which the oxidation of carbon monoxide at low temperatures has been especially well studied ${ }^{10}$. The mechanism is still controversial $^{5}$ although the majority of opinion opts for the effect requiring a discrete gold nano-particle, an oxide support, and a special nanoscale electronic state. However, in contradiction to this we show that mesoporous gold networks are active catalysts too, especially if combined into a nano-composite with oxides such as $\mathrm{Al}_{2} \mathrm{O}_{3}, \mathrm{Fe}_{2} \mathrm{O}_{3}, \mathrm{TiO}_{2}$ and $\mathrm{Co}_{2} \mathrm{O}_{3}$.

Pure mesoporous gold is not particularly active for $\mathrm{CO}$ oxidation, but the prior alloying of $\mathrm{Fe}$ into the $\mathrm{AuAl}_{2}$ precursor produces a very active catalyst ${ }^{4}$. In this case the alloyed $\mathrm{Fe}^{0}$ is converted to $\mathrm{Fe}_{2} \mathrm{O}_{3}$ during the catalysis of $\mathrm{CO}$ oxidation, producing an in situ oxide support. Alternatively, the $\mathrm{AuAl}_{2}$ can be mechanically alloyed with a catalytic support material. Hopcalite $\left(\mathrm{Mn}_{\mathrm{x}} \mathrm{Cu}_{\mathrm{y}} \mathrm{O}_{\mathrm{z}}\right)$, for example, has long been known as a capable of oxidizing $\mathrm{CO}$ at room temperature. However, it deactivates within a few hours. Composite gold- 
hopcalite catalysts prepared by mechanical alloying followed by leaching retain their activity with regard to $\mathrm{CO}$ oxidation for very long times (Figure 2).

Another application for mesoporous gold is in the conversion of $\mathrm{NO}_{\mathrm{x}}$ to nitrogen. There is no place here to discuss the intricacies of this process, save to note that it is a tough task to reduce $\mathrm{NO}_{\mathrm{x}}$ to nitrogen in a gas stream that is super-stoichiometric in oxygen. In contrast to the situation with $\mathrm{CO}$ oxidation, the selective catalytic reduction of $\mathrm{NO}_{\mathrm{x}}$ with propene occurs most readily on the unalloyed sponge ${ }^{11}$ (Figure 3). The oxidation of $\mathrm{NO}$ to $\mathrm{NO}_{2}$ can also be catalyzed, although in this case a gold- $\mathrm{Co}_{2} \mathrm{O}_{3}$ composite has proven to be the more active $^{11}$ (Figure 3).

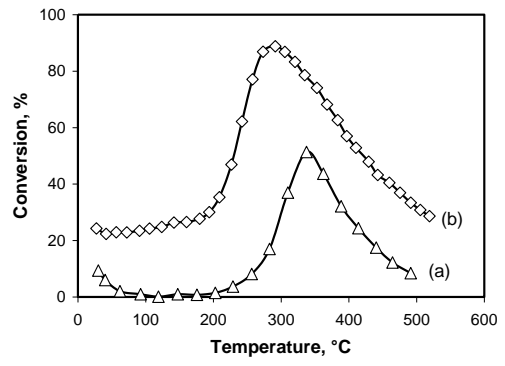

Fig. 3. (a) Selective catalytic reduction of NO to $\mathrm{N} 2$ over mesoporous $\mathrm{Au}$ with propene, (b) catalytic oxidation of $\mathrm{NO}$ to $\mathrm{NO} 2$ over mesoporous $\mathrm{Au} / \mathrm{CoxOy}$ composite. The space velocity in both instances is $601 . \mathrm{g}-1 . \mathrm{h}-1$.

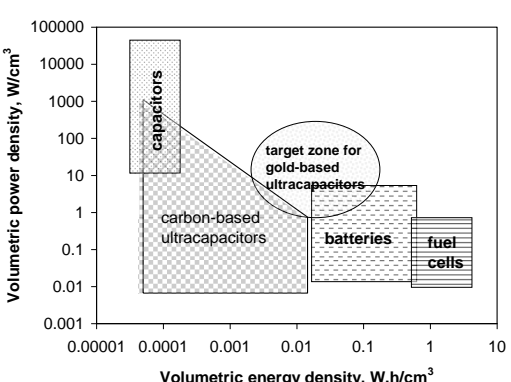

Fig. 4. Volumetric 'Ragone plot' showing the energy/power performance of various storage devices, and the anticipated niche for goldbased ultracapacitors. Based on use of an organic electrolyte with $2.5 \mathrm{~V}$ cell voltage.

\section{Capacitance}

The surface of a charged conductor placed into an liquid containing ions becomes coated with a double-layer of charged ions. If the surface area is very large, as for example for activated carbon at $\sim 1000 \mathrm{~m}^{2} / \mathrm{g}$, then the capacitance can be very large. This effect has recently been exploited by some companies to produce 'ultra-capacitors'. Ultra-capacitors have considerably better power buffering capacities than batteries or ordinary capacitors but are not as good as batteries for storing energy. After accounting for energy lost to internal heating, the peak power $P$ that can be drawn from an ultra-capacitor while discharging it from voltage $V_{0}$ to $1 / 2 V_{0}$ is given by ${ }^{12}$ :

$$
P=\frac{9}{16}\left(1-E_{f}\right) \frac{V_{0}^{2}}{R}
$$

where $E_{\mathrm{f}}$ is the discharge efficiency, and $R$ is the internal resistance. The effect of this is that the power that can be supplied at a given efficiency is inversely proportional to the internal resistance. Since devices based on mesoporous gold should have very much lower resistances than carbon-based ultra-capacitors, 
they should deliver much higher volumetric power density. The maximum energy storage possible in a gold-based ultra-capacitor is not yet known. However, a electrolytic capacitance of 20 to $40 \mu \mathrm{F} / \mathrm{cm}^{2}$ in combination with a surface area of $20 \mathrm{~m}^{2} / \mathrm{g}$, a density of $\sim 7 \mathrm{~g} / \mathrm{cm}^{3}$ and a rapid discharge of 3 to 5 seconds implies that possible power densities of between 1 and $9 \mathrm{~W} / \mathrm{cm}^{3}$ are feasible, in comparison to the $3 \mathrm{~W} / \mathrm{cm}^{3}$ currently available from large carbon based ultra-caps ${ }^{13}$. The possible position of gold-based ultra-capacitors in terms of volumetric power density and energy storage is shown in Figure 4.

\section{Conclusions}

Mesoporous gold can be produced with a surface area of as high as $20 \mathrm{~m}^{2} / \mathrm{g}$ but is susceptible to sintering unless stabilized by an admixture of oxide or other substance. It is an active catalyst for the selective catalytic reduction of $\mathrm{NO}_{\mathrm{x}}$, and, when combined with $\mathrm{Fe}$, an active catalyst for the oxidation of $\mathrm{CO}$. Its high surface area, electrical conductivity and corrosion resistance also suggest its use in ultra-capacitor technology, with volumetric power densities of between 1 and $9 \mathrm{~W} / \mathrm{cm}^{3}$ appearing to be achievable.

\section{Acknowledgement}

This work was supported by Project AuTEK and the World Gold Council

\section{References}

1. M. Raney, US Patent 1628190, 1927.

2. J.B. Friedrich, D.J. Young, and M.S. Wainwright, J. Electrochem. Soc., 128, 1845 (1981).

3. E. Van der Lingen, M.B. Cortie and L. Glaner, South African Patent 2001/5816 (2001) \& PCT patents pending.

4. E. van der Lingen, M.B. Cortie, H. Schwarzer, S.J. Roberts, G. Pattrick, Gold 2003, $28^{\text {th }}$ September- $1^{\text {st }}$ October 2003,Vancouver, Paper 988.

5. M.B. Cortie and E. Van der Lingen, Materials Forum, 26, 1 (2002).

6. D.J. Advena, V.T. Bly, J.T. Cox, Applied Optics, 32(7), 1136 (1993).

7. G.J. Hutchings, J. Catalysis, 96, 292 (1985).

8. M. Haruta, T. Kobayashi, H. Sano, and M. Yamada, Chemistry Letters, p.405 (1987).

9. D. Thompson, Gold Bulletin, 31(4), 111 (1998).

10. D. Thompson, Gold Bulletin, 32(1), 12 (1999).

11. G. Pattrick, E. van der Lingen, H. Schwarzer and S.J. Roberts, Gold 2003, $28^{\text {th }}$ September- $1^{\text {st }}$ October 2003, Vancouver, Paper 993.

12. A. Burke, J. of Power Sources, 91, 37 (2000).

13. M. Cortie and E. van der Lingen, Gold 2003, $28^{\text {th }}$ September- $1^{\text {st }}$ October 2003, Vancouver, Paper 1064. 